\title{
PHYSIOLOGICAL AND PHYSICAL EFFECTS ASSOCIATED WITH TASK CONSTRAINTS, PITCH SIZE, AND FLOATER PLAYER PARTICIPATION IN U-12 $1 \times 1$ SOCCER SMALL-SIDED GAMES
}

original paper

() Wroclaw University of Health and Sport Sciences

DOI: https://doi.org/10.5114/hm.2022.108316

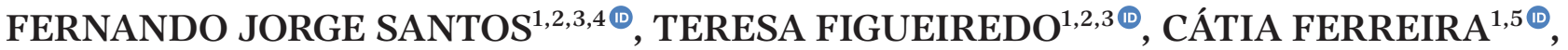 MÁRIO ESPADA ${ }^{1,2,3,6}$ (1)}

${ }^{1}$ School of Education, Polytechnic Institute of Setúbal (ESE, IPS), Setúbal, Portugal

${ }^{2}$ Life Quality Research Centre (CIEQV, ESDRM/IPL), Rio Maior, Portugal

${ }^{3}$ Center for Research in Education and Training (CIEF, IPS), Setúbal, Portugal

${ }^{4}$ Faculty of Human Kinetics, University of Lisbon (FMH, UL), Lisbon, Portugal

${ }^{5}$ Facultad de Ciencias del Deporte de la Universidad de Extremadura (FCD, UNEX), Caceres, Spain

${ }^{6}$ Center for Product Development and Technology Transfer (CDP2T, IPS), Setúbal, Portugal

\begin{abstract}
Purpose. The study aim was to analyse $1 \times 1$ small-sided games (SSGs) with and without floating players, in different pitch sizes.

Methods. Ten U-12 soccer players were divided into 2 groups. Group $1(n=4)$ performed $1 \times 1$ SSG and group $2(n=6)$ performed $1 \times 1+1$ SSG. Field sizes of $5 \times 10 \mathrm{~m}$ (SSG1), $10 \times 15 \mathrm{~m}$ (SSG2), and $15 \times 20 \mathrm{~m}$ (SSG3) were used, all with small goals. The studied variables were heart rate (HR), total distance, explosive distance $(>12 \mathrm{~km} / \mathrm{h})$, accelerations, decelerations, maximum sprint, player load (PL) intensity and volume. The data were collected through WIMU PROTM and analysed with IBM SPSS Statistics. Descriptive analyses and comparisons between the effects of internal and external PL and SSG were performed with the Mann-Whitney $U$ test.
\end{abstract}

Results. Increasing the pitch size in $1 \times 1$ and $1 \times 1+1$ SSGs led to raised total distance, maximum sprint, and PL. In $1 \times 1$ and $1 \times 1+1$ SSGs, the time practice was predominantly associated with $\mathrm{HR}_{\max }$ intervals above $90 \%$. Statistically significant differences were observed between $1 \times 1$ and $1 \times 1+1$ SSGs in explosive distance (SSG2: $46.40 \pm 5.07 / 28.99 \pm 4.93$, $p=0.02, \mathrm{ES}(r)=0.82)$, PL intensity (SSG2: $2.03 \pm 0.11 / 1.78 \pm 0.12, p=0.02, \mathrm{ES}(r)=0.82), \mathrm{HR}_{\max }(\mathrm{SSG} 1: 189.50 \pm 1.91 /$ $199.50 \pm 2.38, p=0.01, \mathrm{ES}(r)=0.82)$, and $\mathrm{HR}_{\text {mean }}(\mathrm{SSG1}: 174.50 \pm 3.31 / 181.75 \pm 2.21, p=0.01, \mathrm{ES}(r)=0.82)$. Floating players' physical and physiological demands were lower compared with the other athletes.

Conclusions. The pitch size influences the physiological and physical response of young soccer players in SSGs. The demand of $1 \times 1$ SSG is higher compared with $1 \times 1+1$. Floating player participation could result in a fruitful strategy to adjust the training intensity of specific soccer players.

Key words: soccer, global positioning system, small-sided games, internal load, external load

\section{Introduction}

Small-sided games (SSGs) are frequently used in team sports, constituting a technical exercise that soccer coaches apply in the training process, regularly manipulating task constraints in view of specific training objectives [1,2]. Physical demands and physiological effects are conditioned by task constraints, pitch size, player numbers, rules, presence/absence of goalkeepers, training regimen, and coach encouragement [3]. The physical effects are the work performed by the players during SSGs, as well as such objective indicators of external load as the distance, sprints, accelerations, decelerations, and parameters derived from accelerometers. The physiological effects are the biological response of players to the practice of SSGs, expressed by

Correspondence address: Fernando Jorge Santos, Instituto Politécnico de Setúbal, Escola Superior de Educação, Centro de Investigação em Qualidade de Vida, Campus do Instituto Politécnico de Setúbal, Estefanilha, 2914-504, Setúbal, Portugal, e-mail: fjlsantos@gmail.com, https://orcid.org/0000-0002-1356-7853

Received: July 13, 2020

Accepted for publication: March 23, 2021

Citation: Santos FJ, Figueiredo T, Ferreira C, Espada M. Physiological and physical effects associated with task constraints, pitch size, and floater player participation in U-12 $1 \times 1$ soccer small-sided games. Hum Mov. 2022;23(4):54-62; doi: https:// doi.org/10.5114/hm.2022.108316. 
internal load heart rate (HR), lactate concentration, and oxygen consumption [4].

Considering the pitch size, several studies indicate that when using large areas, the increase in the physiological response is favoured compared with the use of small areas [3, 5, 6]. Small-field games promote braking, direction changes, accelerations, and decelerations [7-9]. In $1 \times 1$ SSGs, sizes of $5 \times 10 \mathrm{~m}$ are referred to as small, $10 \times 15 \mathrm{~m}$ as medium, and $15 \times 20 \mathrm{~m}$ as large $[10,11]$. The players' work is influenced by the pitch size [3]; the distance, explosive distance, and maximum sprint raise with increasing playing area $[8,9,12,13]$. In studies with under-12 (U-12) players, it was found that an increase in field size promoted an increase in $\mathrm{HR}$, distance travelled, explosive distance, maximum sprint, accelerations, and decelerations [13, 14]. With respect to research on neuromuscular load in SSGs, investigations have used player load (PL) as a valid indicator. PL is a total load indicator calculated through body movements detected by an accelerometer in the 3 anatomical axes of movement [15], presenting a high correlation with the physiological variable of $\mathrm{HR}$ and considered as a valid indicator of analysis and quantification of neuromuscular demands [16]. Zurutuza et al. [9], in small $(3 \times 3)$, medium $(4 \times 4,5 \times 5,6 \times 6)$, and large $(7 \times 7,8 \times 8,9 \times 9)$ SSGs, increasing the playing area per player, observed a decrease in PL (small: $11.9 \pm 2.9$, medium: $11.2 \pm 2.4$, large: $9.8 \pm 2.0$ ). In counter-point, Casamichana et al. [17] found that increasing the pitch size in width and length caused an increase in PL, being, however, more evident with the increase of the field in length owing to the distances covered by vertical running. In the same sense, with U-13 players in large SSGs $(7 \times 7)$ in all formats, an increase in PL was observed as a result of increasing the playing area $\left(100 \mathrm{~m}^{2}, 200 \mathrm{~m}^{2}\right.$, and $300 \mathrm{~m}^{2}$ per player) [18].

The use of a floater player in SSGs influences the team tactical behaviour and other players, promoting the execution of the fundamental game principles, in the context of offensive numerical superiority and defensive numerical inferiority $[19,20]$. The physical demands of floating players are lower than those of the remaining athletes participating in the SSG, so floating players' participation can be a valid strategy to minimize the training load on certain players [21]. Regarding the player numbers, $1 \times 1$ SSGs do not favour tactical training [2], although this soccer training task is important for the work of the specific offensive (penetration) and defensive (containment) principles and increasing technical and physical work [10].
Systematic review studies highlight that there is a need for further deeper understanding of the effects of $1 \times 1$ SSGs [2, 3], a fact that underlines the relevance of examining the internal and external load of $1 \times 1$ and $1 \times 1+1$ SSGs in the U-12 soccer age group when manipulating the constraints of floater player participation and pitch size. In accordance with the aforementioned, we hypothesized that an increase of the playing area would promote an increase of the physiological and physical response, as well as a decrease in the number of accelerations and decelerations and in PL. A lower physiological and physical demand was expected from soccer players involved in $1 \times 1+1$ SSGs in the condition of a floating player participation.

\section{Material and methods}

\section{Participants}

Ten U-12 soccer players participated in the study, divided into 2 distinct groups. Group $1(n=4)$ performed $1 \times 1$ SSG and group $2(n=6)$ performed $1 \times 1$ +1 SSG. The involved young athletes play in a training club framed by the Portuguese Football Federation as a 3-star training entity. They were part of a team competing in regional championships, in the format of 7and 9-a-side soccer. All participants had more than 6 years of experience in soccer practice, in a training process following the club's training model (technical guiding document). The training process respects the stages of development of the young soccer player; SSGs are its integral part for physical, technical, and tactical development to prepare players for teams of age groups higher than U-15, competing in the national championships. The subjects' baseline characteristics are presented in Table 1.

The study followed the guidelines stated in the Declaration of Helsinki [22]. Before starting the research, the objective of the study was explained to club officials and coaches, and authorizations were guaranteed. Parents and players were also informed on the study aims.

Table 1. Participants' characteristics

\begin{tabular}{|c|c|c|c|c|}
\hline $\begin{array}{l}\text { Age } \\
\text { group }\end{array}$ & $\begin{array}{l}\text { Age (years) } \\
M \pm S D\end{array}$ & $\begin{array}{c}\text { Height (m) } \\
M \pm S D\end{array}$ & $\begin{array}{c}\text { Total body } \\
\text { mass (kg) } \\
M \pm S D\end{array}$ & $\begin{array}{c}\text { Body fat }(\%) \\
M \pm S D\end{array}$ \\
\hline $\mathrm{U}-12$ & & & & \\
\hline
\end{tabular}




\section{HUMAN MOVEMENT}

F.J. Santos, T. Figueiredo, C. Ferreira, M. Espada, Physiological and physical effects in $1 \times 1$ soccer SSG

\section{Instruments}

We used the WIMU PRO ${ }^{\mathrm{TM}}$ (RealTrack Systems, Almeria, Spain) inertial devices for data collection. The instrument integrates 4 triaxial accelerometers $(1000 \mathrm{~Hz})$ with a full-scale output range of $\pm 16, \pm 16$, \pm 32 , and $\pm 400 \mathrm{~g} ; 3$ triaxial gyroscopes $(1000 \mathrm{~Hz})$ with a full-scale output range of $2000 \%$ s; a 3-dimensional magnetometer; a 10-Hz global positioning system (GPS) chip; and a 20-Hz ultra-wideband chip [23].

Data were collected via GPS with a sampling frequency of $10 \mathrm{~Hz}$ and motion data through WIMU accelerometers with a sampling frequency of $100 \mathrm{~Hz}$ $[24,25]$. HR data were obtained by using Garmin bands (Olathe, KS, USA) applied by the players, a system that emits data to WIMU PRO ${ }^{\mathrm{TM}}$ devices using the ANT+ technology [26]. Subsequently, the data were removed from WIMU sensors and analysed with the WIMU SPRO computer program (WIMU SPRO, Almeria, Spain).

The WIMU devices provided us with data on the internal load (effect of the load on the body) and the external load (amount of work performed).

Internal load variables

HR expressed as a number of beats per minute (bpm) was examined. We considered $\mathrm{HR}_{\text {max }}, \mathrm{HR}_{\text {mean }}$, and $5 \mathrm{HR}_{\max }$ zones $(60-70 \%, 70-80 \%, 80-90 \%, 90-$ 95\%, and > 95\%) [25].

\section{External load variables}

We investigated the total distance covered (m); explosive distance $(\mathrm{m})$ - distance covered at a speed of $>12 \mathrm{~km} / \mathrm{h}$ [14]; the number of accelerations and decelerations; maximum sprint recorded $(\mathrm{km} / \mathrm{h})$; and PL (a.u.), derived from triaxial accelerometers (x, y, and z), used to evaluate neuromuscular load in different athletes [15, 16].

$$
\begin{gathered}
\mathrm{PL}_{n}=\sqrt{\frac{\left(\mathrm{x}_{n}-\mathrm{x}_{n-1}\right)^{2}+\left(\mathrm{y}_{n}-\mathrm{y}_{n-1}\right)^{2}+\left(\mathrm{z}_{n}-\mathrm{z}_{n-1}\right)^{2}}{100}} \\
\text { Accumulated } \mathrm{PL}=\sum_{n=0}^{m} \mathrm{PL}_{n} \times 0.01
\end{gathered}
$$

\section{Procedures}

The data were collected at the end of March 2019, at the end of the last third of the competitive season. Before the training practice, the WIMU devices were
Table 2. Characteristics of the conditions manipulated in the small-sided games

\begin{tabular}{cccccc}
\hline $\begin{array}{l}\text { Number } \\
\text { of players }\end{array}$ & $\begin{array}{c}\text { Small- Pitch size, } \\
\text { sided } \\
\text { game }\end{array}$ & $\begin{array}{c}\text { Area per } \\
\text { length }(\mathrm{m})\end{array}$ & $\begin{array}{c}\text { player } \\
\left(\mathrm{m}^{2}\right)\end{array}$ & $\begin{array}{c}\text { Time Rest } \\
(\mathrm{min})\end{array}$ \\
\hline $\mathrm{min})$ \\
$1 \times 1$ and & 1 & $5 \times 10$ & 25 and 16.66 & 2 & 3 \\
$1 \times 1+1$ & 2 & $10 \times 15$ & 75 and 50 & 2 & 3 \\
& 3 & $15 \times 20$ & 150 and 100 & 2 & 3 \\
\hline
\end{tabular}

Density $($ work $:$ rest $)=1: 1.5$
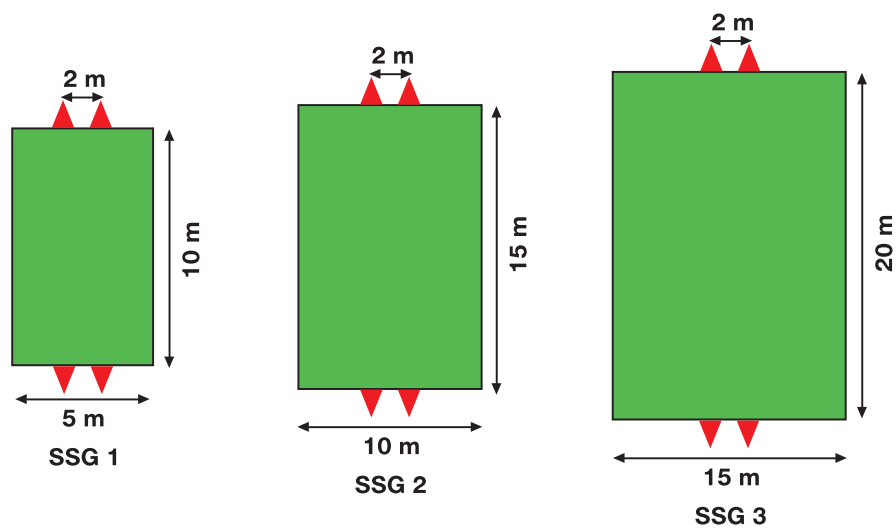

Figure 1. Schematic representation of the small-sided games (SSGs)

properly prepared, personally identified, and distributed to the players. Each training session started with a 15-minute standardized warm-up, followed by the practice of SSGs. The division of players by SSGs was performed in accordance with the guidance of the team coach.

Table 2 and Figure 1 present the details of the SSGs used in the study. Both group $1(1 \times 1)$ and group 2 $(1 \times 1+1)$ performed the 3 SSG formats. The practice of each SSG was 2 minutes, with 3 minutes of rest. Around marked fields, balls were placed, so that there were no game pauses when the ball was out. Two coaches controlled the balls dynamics and another coach managed the duration of the SSGs.

Small goals were used in the 3 SSG formats; we manipulated the pitch size and the participation, or not, of a floating player. The floating players were always involved in the attack phase, not having any kind of restriction of touch movement on the ball or movement on the pitch, which allowed the player in possession of the ball to be in numerical superiority.

\section{Data analysis}

Statistical analysis was performed with the IBM Statistics $24^{\oplus}$ computer program. We conducted a descriptive analysis of the data (mean and standard de- 
viation). The Shapiro-Wilk test indicated that it was not possible to guarantee the normality of the distribution to compare the physiological and physical effects in the different formats of SSGs and in the SSGs with and without the use of a floating player. We therefore chose to employ the Mann-Whitney $U$ test. The effect size $(r)$ was calculated with the following formula:

$$
r=\frac{\mathrm{Z}}{\sqrt{\mathrm{N}}}
$$

The effect size $(r)$ was considered small $(0.10$ to $<$ $0.30)$, medium $(0.30$ to $<0.50)$, or large $(\geq 0.50)$ [27].

\section{Ethical approval}

The research related to human use has complied with all the relevant national regulations and institutional policies, has followed the tenets of the Declaration of Helsinki, and has been approved by the Ethics Committee of the Polytechnic Institute of Leiria (CE/ IPLEIRIA/22/2021).

\section{Informed consent}

Informed consent has been obtained from all individuals included in this study and their legal guardians.

\section{Results}

The results are related to the study of the physiological and physical effects of the $1 \times 1$ SSGs, depending on the floating player participation and the pitch size. Tables 3 and 4 present the descriptive data, as well as the statistical significance of the differences between the SSG formats.

The effect size of field size manipulation (SSG1 vs. SSG2) on the external load variables was large, in $1 \times 1$ format, in accelerations $(\operatorname{ES}(r)=0.51)$ and decelerations $(\operatorname{ES}(r)=0.51)$, and in $1 \times 1+1$ format, in explosive distance $(\mathrm{ES}(r)=0.51)$. Between SSG1 and SSG3, the effect size was large, in $1 \times 1$ format, in accelerations $(\mathrm{ES}(r)=0.56)$ and decelerations $(\mathrm{ES}(r)=$ $0.58)$, and in $1 \times 1+1$ format, in decelerations (ES $(r)$

Table 3. Analysis of external load in the performed SSGs

\begin{tabular}{|c|c|c|c|c|c|c|c|c|c|c|}
\hline \multirow{3}{*}{ Variables } & \multirow{3}{*}{ Players } & \multicolumn{3}{|c|}{ SSG formats } & \multicolumn{6}{|c|}{ Differences between SSG formats } \\
\hline & & \multirow{2}{*}{$\begin{array}{c}\text { (1) } 5 \times 10 \mathrm{~m} \\
M \pm S D\end{array}$} & \multirow{2}{*}{$\begin{array}{l}\text { (2) } 10 \times 15 \mathrm{~m} \\
M \pm S D\end{array}$} & \multirow{2}{*}{$\begin{array}{l}\text { (3) } 15 \times 20 \mathrm{~m} \\
M \pm S D\end{array}$} & \multicolumn{2}{|c|}{1 vs. 2} & \multicolumn{2}{|c|}{1 vs. 3} & \multicolumn{2}{|c|}{2 vs. 3} \\
\hline & & & & & $p$ & $\mathrm{ES}(r)$ & $p$ & $\mathrm{ES}(r)$ & $p$ & $\mathrm{ES}(r)$ \\
\hline \multirow{3}{*}{$\begin{array}{l}\text { Total distance } \\
\text { (m) }\end{array}$} & & & & & 0.02 & 0.82 & 0.02 & & 0.14 & 0.51 \\
\hline & $1 \times 1+1$ & $158 \pm 22.07$ & $165.29 \pm 18.82$ & & 0.56 & 0.20 & 0.02 & & 0.24 & 0.41 \\
\hline & Floaters & $136.15 \pm 2.05$ & $158.60 \pm 38.67$ & $196.84 \pm 9.59$ & 1.00 & 0.00 & 0.12 & 0.77 & 0.43 & 0.39 \\
\hline \multirow{3}{*}{$\begin{array}{l}\text { Explosive } \\
\text { distance (m) }\end{array}$} & & & $46.40 \pm 5.07$ & & 0.02 & & 0.02 & 0.82 & 0.14 & 0.51 \\
\hline & $1 \times 1+1$ & & $28.99 \pm$ & & 0.14 & & 0.24 & & 0.08 & 0.61 \\
\hline & Floaters & & $30.16=$ & & 1.00 & 0.00 & 0.12 & 0.77 & 1.00 & 0.00 \\
\hline \multirow{3}{*}{$\begin{array}{l}\text { Accelerations } \\
\left(\mathrm{m} / \mathrm{s}^{2}\right)\end{array}$} & & & $58.00 \pm 9.38$ & & 0.14 & & 0.11 & & 1.00 & 0.00 \\
\hline & $1 \times 1+1$ & & $66.25 \pm 10.3$ & & 1.00 & & 0.04 & & 0.08 & 0.62 \\
\hline & Floaters & & $66.00 \pm 0.00$ & & 0.31 & 0.50 & 0.12 & 0.77 & 0.10 & 0.82 \\
\hline \multirow{3}{*}{$\begin{array}{l}\text { Decelerations } \\
\left(\mathrm{m} / \mathrm{s}^{2}\right)\end{array}$} & & & 58.2 & & 0.14 & & 0.10 & 0.58 & 0.77 & 0.10 \\
\hline & & & $65.75 \pm 10.34$ & & 1.00 & 0.00 & 0.05 & 0.67 & 0.10 & 0.57 \\
\hline & Floaters & & $66.00 \pm 0.00$ & & 0.31 & 0.50 & 0.12 & 0.77 & 0.10 & 0.82 \\
\hline \multirow{3}{*}{$\begin{array}{l}\text { Maximum } \\
\text { sprint }(\mathrm{km} / \mathrm{h})\end{array}$} & & & $19.44 \pm 0.65$ & $19.82 \pm 0.37$ & 0.02 & 0.77 & 0.02 & 0.82 & 0.56 & 0.20 \\
\hline & $1 \times 1+1$ & & $16.04 \pm 2.36$ & & 0.56 & 0.21 & 0.02 & 0.82 & 0.19 & 0.46 \\
\hline & Floaters & & $16.67 \pm 0.98$ & & 0.43 & 0.39 & 0.12 & 0.77 & 0.22 & 0.61 \\
\hline \multirow{3}{*}{$\begin{array}{l}\text { Player load } \\
\text { (volume) } \\
\text { (a.u.) }\end{array}$} & & $.09 \pm 0.23$ & $4.27 \pm 0.29$ & $4.68 \pm 0.29$ & 0.38 & 0.31 & 0.04 & 0.71 & 0.04 & 0.71 \\
\hline & $1 \times 1+1$ & 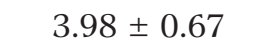 & $3.74 \pm 0.29$ & & 0.77 & 0.10 & 0.77 & 0.10 & 0.77 & 0.10 \\
\hline & Floaters & $3.02 \pm 0.48$ & $3.03 \pm 1.20$ & $3.41 \pm 0.91$ & 1.00 & 0.00 & 0.43 & 0.39 & 0.43 & 0.39 \\
\hline \multirow{3}{*}{$\begin{array}{l}\text { Player load } \\
\text { (intensity) } \\
\text { (a.u.) }\end{array}$} & $1 \times 1$ & $1.93 \pm 0.09$ & $2.03 \pm 0.11$ & $2.24 \pm 0.14$ & 0.56 & 0.21 & 0.02 & 0.82 & 0.04 & 0.72 \\
\hline & & $1.89 \pm 0.28$ & $1.78 \pm 0.12$ & & 1.00 & 0.00 & 0.77 & 0.10 & 0.56 & 0.20 \\
\hline & Floaters & $1.43 \pm 0.19$ & $1.43 \pm 0.48$ & $1.64 \pm 0.43$ & 1.00 & 0.00 & 0.43 & 0.39 & 0.43 & 0.39 \\
\hline
\end{tabular}

SSG - small-sided game

Statistically significant differences at $p<0.05$ 


\section{HUMAN MOVEMENT}

F.J. Santos, T. Figueiredo, C. Ferreira, M. Espada, Physiological and physical effects in $1 \times 1$ soccer SSG

Table 4. Analysis of internal load in the performed SSGs

\begin{tabular}{|c|c|c|c|c|c|c|c|c|c|c|}
\hline \multirow{3}{*}{ Variables } & \multirow{3}{*}{ Players } & \multicolumn{3}{|c|}{ SSG formats } & \multicolumn{6}{|c|}{ Differences between SSG formats } \\
\hline & & \multirow{2}{*}{$\begin{array}{c}(1) 5 \times 10 \mathrm{~m} \\
M \pm S D\end{array}$} & \multirow{2}{*}{ (2) $\begin{array}{l}10 \times 15 \mathrm{~m} \\
M \pm S D\end{array}$} & \multirow{2}{*}{ (3) $\begin{array}{l}15 \times 20 \mathrm{~m} \\
M \pm S D\end{array}$} & \multicolumn{2}{|c|}{1 vs. 2} & \multicolumn{2}{|c|}{1 vs. 3} & \multicolumn{2}{|c|}{2 vs. 3} \\
\hline & & & & & $p$ & $\mathrm{ES}(r)$ & $p$ & $\mathrm{ES}(r)$ & $p$ & $\mathrm{ES}(r)$ \\
\hline \multirow{3}{*}{$\mathrm{HR}_{\max }$} & $1 \times 1$ & $189.50 \pm 1.91$ & $193.75 \pm 3.30$ & $195.75 \pm 3.30$ & 0.08 & 0.62 & 0.02 & 0.77 & 0.55 & 0.21 \\
\hline & $1 \times 1+1$ & $99.50 \pm 2.38$ & $191.25 \pm 15.79$ & $198.25 \pm 3.68$ & 0.88 & 0.05 & 0.76 & 0.10 & 0.66 & 0.15 \\
\hline & Floaters & $186.50 \pm 14.84$ & $175.50 \pm 17.67$ & $186 \pm 19.79$ & 0.43 & 0.39 & 1.00 & 0.00 & 0.43 & 0.39 \\
\hline \multirow{3}{*}{$\mathrm{HR}_{\text {mean }}$} & & $174.50 \pm 3.31$ & $176.75 \pm 3.59$ & $181.5 \pm 4.65$ & 0.55 & 0.21 & 0.04 & 0.72 & 0.11 & 0.56 \\
\hline & $1 \times 1+1$ & & $184.50 \pm 10.37$ & $183.75 \pm 7.13$ & 0.24 & 0.41 & 0.38 & 0.31 & 0.56 & 0.21 \\
\hline & Floaters & $170.50 \pm 12.02$ & $170.50 \pm 24.74$ & $167 \pm 26.87$ & 1.00 & 0.00 & 1.00 & 0.00 & 0.43 & 0.39 \\
\hline \multirow{3}{*}{ HR $60-70 \%^{a}$} & & $5.89 \pm 5.00$ & $0.00 \pm 0.00$ & & 0.01 & 0.87 & 0.56 & 0.21 & 0.13 & 0.53 \\
\hline & $1 \times 1+1$ & 0.00 & $0.00 \pm 0$ & 2.95 & 1.00 & 0.00 & 0.13 & 0.53 & 0.13 & 0.53 \\
\hline & Floaters & $5.91 \pm 8.35$ & $1.13 \pm 1.59$ & $10.72 \pm 15.16$ & 0.68 & 0.20 & 0.68 & 0.20 & 0.43 & 0.39 \\
\hline \multirow{3}{*}{ HR $70-80 \%^{a}$} & & $4.82 \pm 2.31$ & $12.68 \pm 6.51$ & & 0.14 & 0.51 & 1.00 & 0.00 & 0.08 & 0.61 \\
\hline & $1 \times 1+1$ & $8.62 \pm$ & $2.84 \pm 3.82$ & $4.39 \pm 5.17$ & 0.13 & 0.52 & 0.23 & 0.42 & 0.75 & 0.11 \\
\hline & Floaters & $5.21 \pm 7.36$ & $4.83 \pm 6.83$ & $7.3 \pm 7.81$ & 0.68 & 0.20 & 0.43 & 0.39 & 0.43 & 0.39 \\
\hline \multirow{3}{*}{ HR 80-90\% ${ }^{\mathrm{a}}$} & $1 \times 1$ & $6.71 \pm 1.63$ & $11.00 \pm 9.17$ & $6.16 \pm 2.05$ & 0.77 & 0.10 & 0.56 & 0.20 & 0.56 & 0.20 \\
\hline & $1 \times 1+1$ & $10.42 \pm 4.32$ & $9.61 \pm 9.93$ & $5.43 \pm 4.92$ & 0.77 & 0.10 & 0.24 & 0.41 & 0.46 & 0.26 \\
\hline & Floaters & $17.60 \pm 12.98$ & $48.36 \pm 52.11$ & $31.70 \pm 33.09$ & 0.43 & 0.39 & 1.00 & 0.00 & 0.43 & 0.39 \\
\hline \multirow{3}{*}{ HR 90-95\% ${ }^{\mathrm{a}}$} & $1 \times 1$ & $8.11 \pm 3.66$ & $3.75 \pm 1.93$ & $4.98 \pm 3.43$ & 0.08 & 0.61 & 0.19 & 0.46 & 0.56 & 0.20 \\
\hline & $1 \times 1+1$ & $6.52 \pm 6.06$ & $6.54 \pm 7.44$ & $6.77 \pm 6.69$ & 0.77 & 0.10 & 0.77 & 0.10 & 0.77 & 0.10 \\
\hline & Floaters & $21.63 \pm 15.6$ & $2.66 \pm 0.30$ & $9.36 \pm 1.77$ & 0.12 & 0.77 & 0.43 & 0.39 & 0.12 & 0.77 \\
\hline \multirow{3}{*}{$\mathrm{HR}>95 \%^{\mathrm{a}}$} & $1 \times 1$ & $74.45 \pm 4.64$ & $72.56 \pm 7.63$ & $80.00 \pm 5.83$ & 0.56 & 0.20 & 0.14 & 0.51 & 0.08 & 0.61 \\
\hline & $1 \times 1+1$ & $74.43 \pm 4.72$ & $80.99 \pm 20.5$ & $80.45 \pm 4.14$ & 0.24 & 0.41 & 0.14 & 0.41 & 0.56 & 0.20 \\
\hline & Floaters & $49.59 \pm 18.27$ & $43.02 \pm 60.83$ & $40.91 \pm 57.85$ & 1.00 & 0.00 & 1.00 & 0.00 & 0.68 & 0.20 \\
\hline
\end{tabular}

SSG - small-sided game, HR - heart rate

Statistically significant differences at $p<0.05$

a $\% \mathrm{HR}_{\max }$

$=0.67)$ and the floating players in the total distance $(\mathrm{ES}(r)=0.77)$, explosive distance $(\mathrm{ES}(r)=0.77)$, accelerations $(\mathrm{ES}(r)=0.77)$, and decelerations $(\mathrm{ES}(r)=0.77)$. The effect size resulting from the increase in the playing area was also large between SSG2 and SSG3, in $1 \times 1$ format, in total distance $(\mathrm{ES}(r)=0.51)$ and explosive distance $(\operatorname{ES}(r)=0.51)$, and in $1 \times 1+1$ format, in explosive distance $(\mathrm{ES}(r)=0.61)$, accelerations $(\mathrm{ES}(r)=0.62)$, decelerations $(\mathrm{ES}(r)=0.57)$, and floaters in accelerations $(\mathrm{ES}(r)=0.82)$, decelerations $(\mathrm{ES}(r)=$ $0.82)$, and maximum sprint $(\mathrm{ES}(r)=0.61)$.

Table 4 shows the existence of significant differences in $1 \times 1$ format between SSG1 and SSG2 in HR 60$70 \%(5.89 \pm 5.00 / 0.00 \pm 0.00, p=0.01, \mathrm{ES}(r)=0.87)$ and between SSG1 and SSG3 at $\mathrm{HR}_{\max }(189.50 \pm 1.91$ $/ 195.75 \pm 3.3, p=0.02, \operatorname{ES}(r)=0.77)$ and $\mathrm{HR}_{\text {mean }}$ $(174.50 \pm 3.31 / 181.5 \pm 4.65, p=0.04, \mathrm{ES}(r)=0.72)$. The increase of the area in SSG1/SSG2 had a large effect size in $1 \times 1$ format on $\mathrm{HR}_{\max }(\mathrm{ES}(r)=0.62)$, HR
$60-70 \%(\mathrm{ES}(r)=0.87)$, HR $70-80 \%(\mathrm{ES}(r)=0.51)$, and HR $90-95 \%(\mathrm{ES}(r)=0.61)$, and in $1 \times 1+1$ format on HR $70-80 \%(\mathrm{ES}(r)=0.52)$. The field size increase (SSG1 vs. SSG3) had a large effect size in $1 \times 1$ format on $\mathrm{HR}_{\text {max }}(\mathrm{ES}(r)=0.77), \mathrm{HR}_{\text {mean }}(\mathrm{ES}(r)=0.72)$, and $\mathrm{HR}>95 \%(\mathrm{ES}(r)=0.51)$, and in $1 \times 1+1$ format on HR $60-70 \%(\mathrm{ES}(\mathrm{r})=0.53)$ and $\mathrm{HR}>95 \%(\mathrm{ES}(r)=0.51)$. Regarding increasing pitch size in SSG2 vs. SSG3, we verified a large effect in $1 \times 1$ format on $\mathrm{HR}_{\text {mean }}(\mathrm{ES}(r)=$ $0.56)$, HR $60-70 \%(\mathrm{ES}(r)=0.53)$, HR 70-80\% $(\mathrm{ES}(r)=$ $0.61)$, and HR $>95 \%(\mathrm{ES}(r)=0.61)$, and in $1 \times 1+1$ format on HR $60-70 \%(\mathrm{ES}(r)=0.51)$ and in float players on HR 90-95\% $(\mathrm{ES}(r)=0.77)$.

Figure 2 presents the boxplot graphs for a 95\% confidence interval and statistically significant differences between players in the $1 \times 1$ and $1 \times 1+1$ SSG formats in each field dimension.

In Figure 2, we can observe the differences between the internal and external load relative to participants 

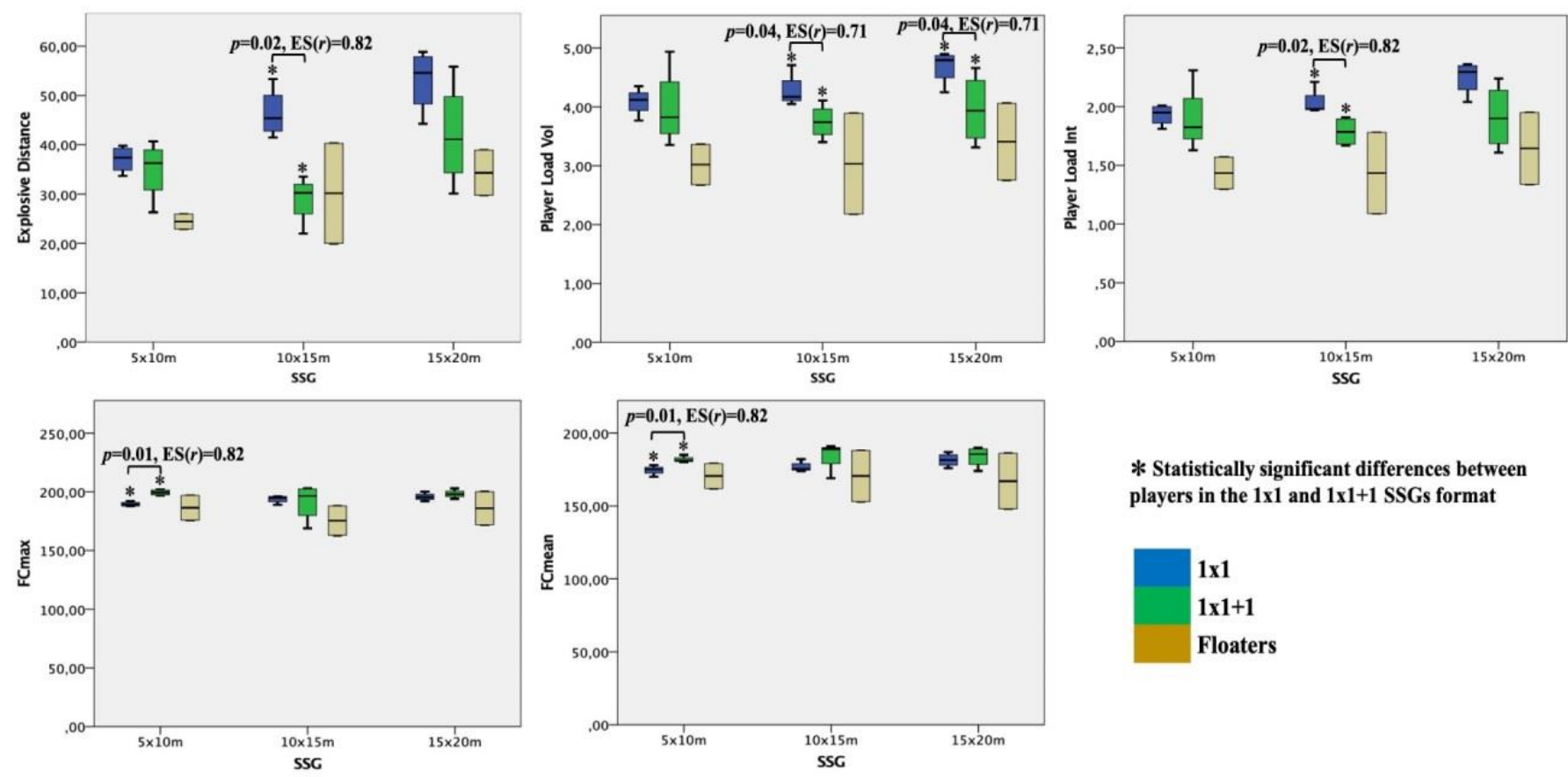

\section{* Statistically significant differences between players in the 1x1 and 1x1+1 SSGs format}
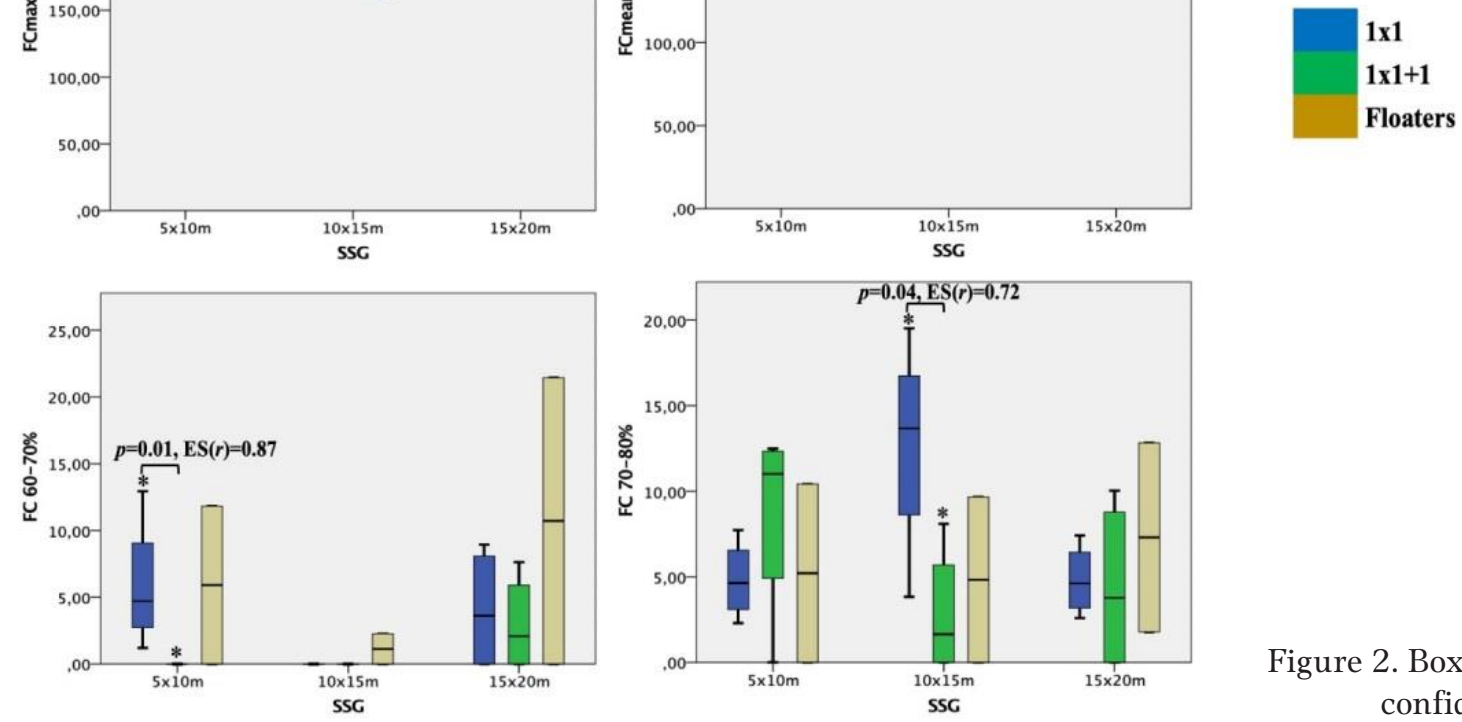

Figure 2. Boxplot graphs for a 95\% confidence interval

FC - heart rate, SSG - small-sided game

who played $1 \times 1,1 \times 1+1$, and floaters. In SSG1 $(5 \times 10 \mathrm{~m})$, we found statistically significant differences between $1 \times 1$ and $1 \times 1+1$ in $\operatorname{HR}_{\max }(189.50 \pm$ $1.91 / 199.50 \pm 2.38, p=0.02, \mathrm{ES}(r)=0.82), \mathrm{HR}_{\text {mean }}$ $(174.5 \pm 3.31 / 181.75 \pm 2.21, p=0.01, \mathrm{ES}(r)=0.82)$, and $60-70 \% \mathrm{HR}_{\max }(5.89 \pm 5.00 / 0.00 \pm 0.00, p=0.01$, $\mathrm{ES}(r)=0.87)$.

In SSG2 $(10 \times 15 \mathrm{~m})$, we revealed significant differences between players in $1 \times 1$ and $1 \times 1+1$ in the explosive distance $(46.40 \pm 5.07 / 28.99 \pm 4.93, p=$ $0.02, \mathrm{ES}(r)=0.82)$, PL volume $(4.27 \pm 0.29 / 3.74 \pm$ $0.29, p=0.04, \mathrm{ES}(r)=0.71)$, PL intensity $(1.78 \pm 0.12$ $/ 1.43 \pm 0.48, p=0.02, \mathrm{ES}(r)=0.82)$, and $70-80 \%$ of $\mathrm{HR}_{\max }(12.68 \pm 6.51 / 2.84 \pm 3.82, p=0.04, \mathrm{ES}(r)=$ 0.72).

SSG3 $(15 \times 20 \mathrm{~m})$ was associated with significant differences between $1 \times 1$ and $1 \times 1+1$ in the PL volume $(3.96 \pm 0.6 / 3.41 \pm 0.91, p=0.04, \mathrm{ES}(r)=0.71)$.

In SSG1, the effect size was large, considering the use or not of float players $(1 \times 1$ vs. $1 \times 1+1)$ in HR $80-90 \%(\mathrm{ES}(r)=0.51)$. In the comparison between
$1 \times 1$ players and floats, we determined a large effect size in total distance $(\mathrm{ES}(r)=0.76)$, explosive distance $(\mathrm{ES}(r)=0.76)$, maximum sprint $(\mathrm{ES}(r)=0.76)$, PL volume $(\mathrm{ES}(r)=0.76)$, PL intensity $(\mathrm{ES}(r)=0.76)$, HR $80-90 \%$ $(\mathrm{ES}(r)=0.57), \mathrm{HR} 90-95 \%(\mathrm{ES}(r)=0.57)$, and HR > $95 \%(\mathrm{ES}(r)=0.76)$. In the comparison between $1 \times 1+1$ players and float players, we demonstrated a large effect size on explosive distance $(\mathrm{ES}(r)=0.76)$, decelerations $(\mathrm{ES}(r)=0.68)$, maximum sprint $(\mathrm{ES}(r)=0.57)$, PL volume $(\mathrm{ES}(r)=0.76)$, PL intensity $(\mathrm{ES}(r)=0.67)$, $\mathrm{HR}_{\text {max }}(\mathrm{ES}(r)=0.77), \mathrm{HR}_{\text {mean }}(\mathrm{ES}(r)=0.77), \mathrm{HR} 60-70 \%$ $(\mathrm{ES}(r)=0.58)$, HR $90-95 \%(\mathrm{ES}(r)=0.57)$, and HR $>95 \%$ $(\mathrm{ES}(r)=0.76)$.

In SSG2, the use or not of float players promoted a large weight of achievement in the variables of total distance $(\mathrm{ES}(r)=0.51)$ and maximum sprint $(\mathrm{ES}(r)=$ $0.61)$. Between $1 \times 1$ players and float players, we verified a large effect size on explosive distance $(\mathrm{ES}(r)=$ $0.76)$, accelerations $(\mathrm{ES}(r)=0.78)$, decelerations $(\mathrm{ES}(r)=$ $0.78)$, maximum sprint $(\mathrm{ES}(r)=0.76)$, PL volume $(\mathrm{ES}(r)=$ $0.76)$, PL intensity $(\mathrm{ES}(r)=0.77), \mathrm{HR}_{\max }(\mathrm{ES}(r)=0.77)$, 
F.J. Santos, T. Figueiredo, C. Ferreira, M. Espada, Physiological and physical effects in $1 \times 1$ soccer SSG

HR $60-70 \%(\mathrm{ES}(r)=0.58), \mathrm{HR} 70-80 \%(\mathrm{ES}(r)=0.57)$, and HR $80-90 \%(\mathrm{ES}(r)=0.57)$. When comparing $1 \times 1+1$ players and float players, the effect size was large in $\mathrm{HR}_{\text {max }}(\mathrm{ES}(r)=0.57), \mathrm{HR}_{\text {mean }}(\mathrm{ES}(r)=0.58)$, and HR 60-70\% $(\mathrm{ES}(r)=0.58)$.

Regarding SSG3, comparing the players of $1 \times 1$ and $1 \times 1+1$, we revealed a large effect size in explosive distance $(\operatorname{ES}(r)=0.61)$ and PL intensity $(\operatorname{ES}(r)=$ $0.67)$. Among $1 \times 1$ players and float players, the effect size was large in the explosive distance variables $(\mathrm{ES}(r)$ $=0.76)$, PL volume $(\mathrm{ES}(r)=0.76)$, and PL intensity $(\mathrm{ES}(r)=0.76)$.

\section{Discussion}

This study aimed to analyse the physiological and physical effects of the practice of different SSG formats, $1 \times 1$ and $1 \times 1+1$ in U-12 players, manipulating the pitch size constraints. Another subject of comparative analysis was the internal and external load evidenced by the floating soccer players with reference to the different pitch sizes.

In what concerns $1 \times 1$ SSG, the results confirmed the hypotheses related to the effects on the internal and external load. The increase in the pitch size promoted a rise of physiological effects (HR), a fact more evident with the greater significance in the larger playing areas, in line with previous studies [2, 3, 5, 6]. It was possible to verify that the playing area increase promoted a large effect size in HR, as previously observed in studies conducted with players of the same age (U-12) [14, 28]. In the $1 \times 1$ SSG, we demonstrated a great intensity in physiological terms, normally associated with extreme games, since higher values of $\mathrm{HR}>95 \%$ and $\mathrm{HR}_{\max }$ were recorded. Studies conducted with athletes older than those in our investigation found HR of $88-89 \% \mathrm{HR}_{\max }$ in $1 \times 1$ SSG [29, 30]. As for the external load, the results are in line with the expectations $[8,9,12]$. There was an increase in total distance, explosive distance, and maximum sprint with the increase in pitch size. Studies with U-12 players involving manipulation of the playing area reported an increase in the same variables as a result of an increase in the field size $[13,14]$. The total number of accelerations and decelerations was higher for the smaller playing area. The fact that small areas of play promote accelerations and decelerations [7-9] was more evident between SSG1 and SSG3 $(5 \times 10 \mathrm{~m}$ vs. $15 \times$ $20 \mathrm{~m}$ ). Regarding PL values, as a variable that translates body load in the 3 axes (vertical, anterior-posterior, and mediolateral), important to evaluate the neuromuscular load $[15,16]$, we verified an increase in the
$1 \times 1$ SSG with concomitant increase of the playing area. From the results obtained, we can assume that the pitch size increase promotes a reduction of accelerations/decelerations and an increase in PL. This metric is a measure derived from the accelerometers of body load at the present instant and instant immediately preceding [16]. In the present study, we found an increase in PL volume and PL intensity concomitant to the playing area increase, being a large effect size between SSG1 and SGG3, and SSG2 and SSG3. In soccer, accelerations and decelerations $>3 \mathrm{~m} / \mathrm{s}^{2}$ are fundamental; however, we took into account the total number of accelerations and decelerations, which may not demonstrate in which format there were higher loads in neuromuscular terms. The $1 \times 1$ SSG promotes many ball losses and recoveries, resulting in constant accelerations and decelerations, and these are more intense in the larger playing areas.

In the $1 \times 1+1$ SSG, we recorded the same direction of results in physical effects (total distance, maximum sprint, and PL) in relation to $1 \times 1$ SSG, considering the pitch size manipulation. However, the only statistically significant differences were reported in the total distance and maximum sprint between SSG1 and SSG3. In SSG1 and SSG2, we observed approximate values of accelerations/decelerations, but there was a significant decrease in these variables in SSG3 (largest playing area). Regarding the physiological response (HR), we found that it was not linear to playing area increase, and a large percentage of work occurred in the $>90 \% \mathrm{HR}_{\max }$. However, we observed a big effect on HR $60-70 \%$ increase in SSG1 vs. SSG3 and SSG2 vs. SSG3, and a decrease in HR 70-80\% in SSG1 vs. SSG2. The results seem to imply that the introduction of a floating player promotes an increase in the greater physiological load. With respect to body load, comparing $1 \times 1$ vs. $1 \times 1+1$, we demonstrated that the increase in the playing area had a great effect on PL, which shows that the introduction of a floating player causes a decrease of players' neuromuscular activity. We can also add that the increase in the playing area in the $1 \times 1+1$ SSG has a small effect on neuromuscular work.

In relation to the floating players, we found that the external and internal load were lower compared with the other players, which is in line with the hypothesis raised by us and indicated by Rábano-Muñoz et al. [21]. However, we must point out that owing to the constant transience of the $1 \times 1$ game, close values in accelerations/decelerations and maximum sprint were observed when comparing floaters and other players. In view of the record, we can suggest that floating 
players should be considered for specific work [21] of reintegration after stoppage or injury and may also be an important strategy for tactical work in the context of the principles of play, such as offensive superiority and defensive inferiority [19, 20].

In practical terms, we can mention that the $1 \times 1$ SSG promotes a high level of intensity and neuromuscular activity resulting from constant accelerations, decelerations, and braking. Increasing the pitch size raises total distance covered, explosive distance, and maximum sprint. It is evident that the use of a floating player $(1 \times 1+1)$ has a great effect on the decrease in external load, although it promotes the effects on the level of internal load (HR). The floating players evidenced lower values than the other cohorts concerning the level of internal and external load; hence, we suggest that this task in the training environment is appropriate for soccer players who were recently inactive (illness, injury, or other); however, it is necessary to pay attention to greater neuromuscular activity due to the constant transition resulting from the loss of the ball in the $1 \times 1$.

As the study limitation, we can consider the fact that the players who participated in $1 \times 1$ were different from those involved in $1 \times 1+1$. However, it will be important to point out that the athletes had belonged to the same team since the U-8 age groups and that the training process was guided by the club's training model. Another limitation is related to the small number of participants and the fact that the soccer players belonged to a single age group (U-12); consequently, these results should be carefully monitored in other age groups. Finally, as each player's observation was not performed in both game formats, this analysis could not occur. Future research should consider a larger sample in the same age group and other age groups, with and without floating players, with and without goalkeepers, to verify the potential of the $1 \times 1$ SSG from a physiological, physical, and technical perspective.

\section{Conclusions}

The increase in pitch size in the $1 \times 1$ SSG promotes an increase in physiological effects (HR) and physical demands in the total distance covered, explosive distance, maximum sprint, and PL. The increase in the playing area reduces accelerations and decelerations. The values of raised PL, with the increase in pitch size, deserve special attention since they indicate that despite the accelerations/decelerations decrease, there is an increase in neuromuscular activity.
In the $1 \times 1+1$ SSG, the increase in pitch size promotes an increase in HR, total distance covered, explosive distance, and maximum sprint. The introduction of a floating player raises intensity in physiological terms and lowers the effects of neuromuscular work. As for physical effects, $1 \times 1$ SSGs proved to be more demanding compared with $1 \times 1+1$ SSGs. The floating players evidence lower physiological and physical effects than other players.

This study is important for young soccer coaches, since it provides relevant indications, from the physiological and physical perspective, as to the handling of constraints of the play area task and introduction of a floating player in $1 \times 1$ SSGs. However, these results should be analysed with caution and with respect to the age group in which the study was conducted.

\section{Acknowledgements}

The study was supported by the Portuguese Foundation for Science and Technology, I.P., grant/award No. UID/04748/2020.

\section{Disclosure statement}

No author has any financial interest or received any financial benefit from this research.

\section{Conflict of interest}

The authors state no conflict of interest.

\section{References}

1. Sannicandro I, Cofano G. Small-sided games activities with external wildcard soccer players. MOJ Sports Med. 2018;2(4):128-131; doi:10.15406/mojsm.2018.02.00060.

2. Sarmento H, Clemente FM, Harper LD, da Costa IT, Owen A, Figueiredo AJ. Small sided games in soccer a systematic review. Int J Perform Anal Sport. 2018; 18(5):693-749; doi:10.1080/24748668.2018.1517288.

3. Bujalance-Moreno P, Latorre-Román PÁ, García-Pinillos F. A systematic review on small-sided games in football players: acute and chronic adaptations. J Sports Sci.2019;37(8):921-949; doi:10.1080/02640414.2018. 1535821.

4. Bourdon PC, Cardinale M, Murray A, Gastin P, Kellman M, Varley MC, et al. Monitoring athlete training loads: consensus statement. Int J Sports Physiol Perform. 2017;12(Suppl. 2):S2161-S2170; doi: 10.1123/ IJSPP.2017-0208.

5. Owen A, Twist C, Ford P. Small-sided games: the physiological and technical effect of altering pitch size and player numbers. Insight. 2004;7(2):50-53.

6. Casamichana D, Castellano J. Time-motion, heart rate, perceptual and motor behaviour demands in smallsides soccer games: effects of pitch size. J Sports Sci. 2010;28(14):1615-1623; doi:10.1080/02640414.2010. 521168 . 
F.J. Santos, T. Figueiredo, C. Ferreira, M. Espada, Physiological and physical effects in $1 \times 1$ soccer SSG

7. Clemente F, Couceiro MS, Martins FML, Mendes R. The usefulness of small-sided games on soccer training. J Phys Educ Sport. 2012;12(1):93-102.

8. Martin-Garcia A, Castellano J, Gomez Diaz A, Cos F, Casamichana D. Positional demands for various-sided games with goalkeepers according to the most demanding passages of match play in football. Biol Sport. 2019; 36(2):171-180; doi: 10.5114/biolsport.2019.83507.

9. Zurutuza U, Castellano J, Echeazarra I, Guridi I, Casamichana D. Selecting training-load measures to explain variability in football training games. Front Psychol. 2020;10:2897; doi: 10.3389/fpsyg.2019.02897.

10. Clemente FM, Martins FML, Mendes RS. Periodization based on small-sided soccer games: theoretical considerations. Strength Cond J. 2014;36(5):34-43; doi: 10.1519/SSC.0000000000000067.

11. Little T. Optimizing the use of soccer drills for physiological development. Strength Cond J. 2009;31(3):6774; doi: 10.1519/SSC.0b013e3181a5910d.

12. Nunes NA, Gonçalves B, Davids K, Esteves P, Travassos B. How manipulation of playing area dimensions in ball possession games constrains physical effort and technical actions in under-11, under-15 and under-23 soccer players. Res Sports Med. 2021;29(2):170-184; doi: 10.1080/15438627.2020.1770760.

13. Castillo D, Raya-González J, Clemente FM, Yanci J. The influence of offside rule and pitch sizes on the youth soccer players' small-sided games external loads. Res Sports Med. 2020;28(3):324-338; doi: 10.1080/1543 8627.2020.1739687.

14. Santos FJ, Figueiredo T, Ferreira C, Espada M. Physiological and physical effect on U-12 and U-15 football players, with the manipulation of task constraints: field size and goalkeeper in small-sided games of $4 \times 4$ players. Rev Int Cienc Deporte. 2021;63(17):13-24; doi: 10.5232/ricyde2021.06302.

15. Reche-Soto P, Cardona-Nieto D, Diaz-Suarez A, Bastida-Castillo A, Gomez-Carmona C, Garcia-Rubio J, et al. Player load and metabolic power dynamics as load quantifiers in soccer. J Hum Kinet. 2019;69(1):259269; doi: 10.2478/hukin-2018-0072.

16. Reche-Soto P, Cardona D, Díaz A, Gómez-Carmona C, Pino-Ortega J. AcelT and player load: two variables to quantify neuromuscular load. Rev Int Med Cienc Act Fis Deporte. 2020;20(77):167-183; doi: 10.15366/rimcafd2020.77.011.

17. Casamichana D, Bradley PS, Castellano J. Influence of the varied pitch shape on soccer players physiological responses and time-motion characteristics during small-sided games. J Hum Kinet. 2018;64:171-180; doi: 10.1515/hukin-2017-0192.

18. Castellano J, Puente A, Echeazarra I, Casamichana D. Influence of the number of players and the relative pitch area per player on heart rate and physical demands in youth soccer. J Strength Cond Res. 2015;29(6):16831691; doi: 10.1519/JSC.0000000000000788.

19. Moniz F, Scaglia A, Sarmento H, García-Calvo T, Teoldo I. Effect of an inside floater on soccer players tactical behaviour in small sided and conditioned games. J Hum Kinet. 2020;71:167-177; doi: 10.2478/hukin-2019-0080.

20. Bach Padilha M, Guilherme J, Serra-Olivares J, Roca A, Teoldo I. The influence of floaters on players' tactical behaviour in small-sided and conditioned soccer games. Int J Perform Anal Sport. 2017;17(5):721-736; doi: 10.1080/24748668.2017.1390723.

21. Rábano-Muñoz A, Asian-Clemente J, Sáez de Villarreal E, Nayler J, Requena B. Age-related differences in the physical and physiological demands during smallsided games with floaters. Sports. 2019;7(4):79; doi: 10.3390/sports7040079.

22. Harriss DJ, Atkinson G. Update - ethical standards in sport and exercise science research. Int J Sports Med. 2011;32(11):819-821; doi: 10.1055/s-0031-1287829.

23. Granero-Gil P, Bastida-Castillo A, Rojas-Valverde D, Gómez-Carmona CD, de la Cruz Sánchez E, Pino-Ortega J. Influence of contextual variables in the changes of direction and centripetal force generated during an elite-level soccer team season. Int J Environ Res Public Health. 2020;17(3):967; doi: 10.3390/ijerph17030967.

24. Bastida Castillo A, Gómez Carmona CD, De la Cruz Sánchez E, Pino Ortega J. Accuracy, intra- and inter-unit reliability, and comparison between GPS and UWBbased position-tracking systems used for time-motion analyses in soccer. Eur J Sport Sci. 2018;18(4):450457; doi: 10.1080/17461391.2018.1427796.

25. Gómez-Carmona CD, Gamonales JM, Pino-Ortega J, Ibáñez SJ. Comparative analysis of load profile between small-sided games and official matches in youth soccer players. Sports. 2018;6(4):173; doi: 10.3390/sports60 40173.

26. Molina-Carmona I, Gómez-Carmona C, Bastida-Castillo A, Pino-Ortega J. Validity of WIMU PRO ${ }^{\mathrm{tm}}$ inertial device to register heart rate variable in a field test [in Spanish]. Sport TK. 2018;7(1):81-86; doi: 10.6018/ 321921.

27. Fritz CO, Morris PE, Richler JJ. Effect size estimates: current use, calculations, and interpretation. J Exp Psychol Gen. 2012;141(1):2-18; doi: 10.1037/a0024338.

28. Martone D, Giacobbe M, Capobianco A, Imperlini E, Mancini A, Capasso M, et al. Exercise intensity and technical demands of small-sided soccer games for under-12 and under-14 players: effect of area per player. J Strength Cond Res. 2017;31(6):1486-1492; doi: 10.1519/JSC.0000000000001615.

29. Ade JD, Harley JA, Bradley PS. Physiological response, time-motion characteristics, and reproducibility of various speed-endurance drills in elite youth soccer players: small-sided games versus generic running. Int J Sports Physiol Perform. 2014;9(3):471-479; doi: 10.1123/ijspp.2013-0390.

30. Köklü Y, Aşçi A, Koçak FÜ, Alemdaroğlu U, Dündar U. Comparison of the physiological responses to different small-sided games in elite young soccer players. J Strength Cond Res. 2011;25(6):1522-1528; doi: 10.1519/ JSC.0b013e3181e06ee1. 